\title{
Design of a compact size UWB planar antenna with WiMAX band rejection
}

\author{
Emad Tammam ${ }^{1}$, Lingsheng Yang ${ }^{2}$, Kuniaki Yoshitomi ${ }^{3 a)}$, \\ Ahmed Allam ${ }^{1}$, Mohammed Ragab ${ }^{1}$, Haruichi Kanaya ${ }^{2}$, \\ and Keiji Yoshida ${ }^{3}$ \\ ${ }^{1}$ School of Electronics, Communications, and Computer Engineering, \\ Egypt-Japan University of Science and Technology, Alexandria 21934, Egypt \\ ${ }^{2}$ Graduate School of Information Science and Electrical Engineering, \\ Kyushu University, 744 Motooka, Nishi-ku, Fukuoka 819-0395, Japan \\ ${ }^{3}$ E-JUST Center, Kyushu University, 744 Motooka, Nishi-ku, Fukuoka 819-0395, \\ Japan \\ a)yoshitomi@ejust.kyushu-u.ac.jp
}

\begin{abstract}
A compact monopole ultra-wideband (UWB) antenna with WiMAX band rejection is proposed. The proposed antenna is optimized to be $12 \times 18 \mathrm{~mm}^{2}$ in size and cover the frequency band from 3.1 to $11 \mathrm{GHz}$ with rejection of the WiMAX band. The antenna is simulated, fabricated, and tested; the measured results show good agreement with the simulation results. The proposed antenna presents satisfactory radiation characteristics.
\end{abstract}

Keywords: UWB antenna, compact size, WiMAX band rejection Classification: Microwave and millimeter wave devices, circuits, and systems

\section{References}

[1] J. Jung, W. Choi, and J. Choi, "A small wideband microstrip-fed monopole antenna," IEEE Microw. Wireless Compon. Lett., vol. 15, no. 10, pp. 703-705, Oct. 2005.

[2] K. Bahadori and Y. Rahmat-Samii, "A miniaturized elliptic-card UWB antenna with WLAN band rejection for wireless communications," IEEE Trans. Antennas Propag., vol. 55, no. 11, pp. 3326-3332, Nov. 2007.

[3] S. Radiom, H. Aliakbarian, G. A. E. Vandenbosch, and G. G. E. Gielen, "An effective technique for symmetric planar monopole antenna miniaturization," IEEE Trans. Antennas Propag., vol. 57, no. 10, pp. 2989-2996, Oct. 2009.

[4] M. N. Moghadasi, H. Rousta, and B. S. Virdee, "A highly compact semielliptic shape ultrawideband monopole antenna," Microwave and Optical Technology Letters, vol. 53, no. 1, pp. 229-231, Jan. 2011.

[5] P. Tilanthe, P. C. Sharma, and T. K. Bandopadhyay, "A compact UWB antenna with dual band rejection," Progress in Electromagnetics Research $B$, vol. 35, pp. 389-405, 2011.

[6] A. A. Gheethan and D. E. Anagnostou, "Dual band-reject UWB antenna with sharp rejection of narrow and closely-spaced bands," IEEE Trans. 
Antennas Propag., vol. 60, no. 4, pp. 2071-2076, April 2012.

[7] K. Chung, J. Kim, and J. Choi, "Wideband microstrip-fed monopole antenna having frequency band-notch function," IEEE Microw. Wireless Compon. Lett., vol. 15, no. 11, pp. 766-768, Nov. 2005.

\section{Introduction}

Nowadays, wireless communication systems are becoming increasingly popular. However, the technologies for wireless communication still need to be improved further to satisfy the higher resolution and data rate requirements [1]. One of the important improvements in the field of the wireless communications is the emerging of the ultra-wideband (UWB) technology. The spectrum from 3.1 to $10.6 \mathrm{GHz}$ is allocated by the Federal Communication Commission (FCC) for unlicensed UWB measurements and communications applications of low power and short range $(<10 \mathrm{~m})[2]$ to enable high capacity data transmission. In the last ten years, the interest in UWB systems has grown as they not only promise enhanced data throughput with low power consumption, but also provide high immunity against electromagnetic interference (EMI) and robustness to fading [3].

Until recently, much effort has been expended by researchers in academia and industry to overcome the technical difficulties in the development of UWB system, in particular antennas that satisfy the stringent regulation of spectrum mask defined by FCC [4]. A good UWB antenna should be capable of operating over the bandwidth assigned by the FCC. At the same time a small and compact antenna size is highly desirable, due to the integration requirement of UWB systems. Also reasonable efficiency and satisfactory radiation properties over the entire frequency range are necessary. Another key requirement of UWB antennas is good time domain behavior, i.e., a good impulse response and minimal distortion [5]. Moreover, the frequency range of the UWB systems is shared by some other communication systems such as the worldwide interoperability for microwave access (WiMAX) system which uses the licensed frequency of $3.5 \mathrm{GHz}$ for indoor fixed systems in many countries worldwide. The UWB antenna that receives typically a few nanowatts from UWB signal will also receive interfering signal from coexisting communication systems [6]. Therefore, an UWB antenna with band-notch characteristics is required to mitigate the interference between the two systems.

Several antennas with band-notch characteristics has been reported [7]. However, the size of these antennas was relatively large making the integration of these antennas to the integration circuits is difficult.

In this work, a compact size UWB monopole antenna with WiMAX band rejection is proposed. The main advantage of this antenna is its small size and simple configuration which make it easy to be fabricated. The physical size of the antenna has been strictly optimized to be $12 \times 18 \mathrm{~mm}^{2}$ which is a too compact size compared to many other antennas which work at the same 
frequency band. The antenna presents a satisfactory performance either in respect to the impedance matching or the radiation characteristics. The band rejection characteristic of the antenna is achieved using a simple curved slot printed on the radiating patch. The length of the slot is optimized to be $\lambda / 2$ at the center frequency of the rejected band while the rejected bandwidth is controlled by the thickness and position of the slot.

\section{Antenna configuration}

The configuration of the proposed antenna is shown in Fig. 1 (a) and 1 (b). The antenna is monopole with U-shaped radiator and truncated ground plane. A small half circle is etched in the ground plane to aid the impedance matching of the antenna and a curved slot is printed on the radiator to provide the WiMAX band rejection. The antenna is fabricated on FR4 substrate with dielectric constant of $\varepsilon_{r}=4.25$, tangent loss of 0.015 , thickness of $1.6 \mathrm{~mm}$. The substrate's length $L_{\text {sub }}=18 \mathrm{~mm}$ and the width $W_{\text {sub }}=12 \mathrm{~mm}$. The rest of the antenna's dimensions are as follows: $L_{g}=5.5 \mathrm{~mm}, L_{e}=3.5 \mathrm{~mm}$, $W_{f}=2.5 \mathrm{~mm}, r_{g}=3 \mathrm{~mm}, t=1 \mathrm{~mm}, k=5.5 \mathrm{~mm}, d=3 \mathrm{~mm}, s=0.5 \mathrm{~mm}$, $u=0.5 \mathrm{~mm}, v=2.5 \mathrm{~mm}, L_{1}=1.6 \mathrm{~mm}, L_{2}=0.4 \mathrm{~mm}, L_{3}=0.9 \mathrm{~mm}$, $r_{1}=3 \mathrm{~mm}, r_{2}=4.2 \mathrm{~mm}, r_{3}=4.4 \mathrm{~mm}$, and $r_{4}=6 \mathrm{~mm}$. The photograph

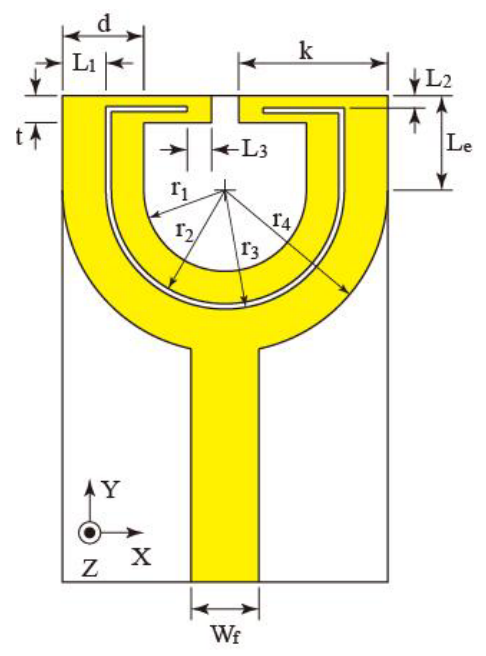

(a)

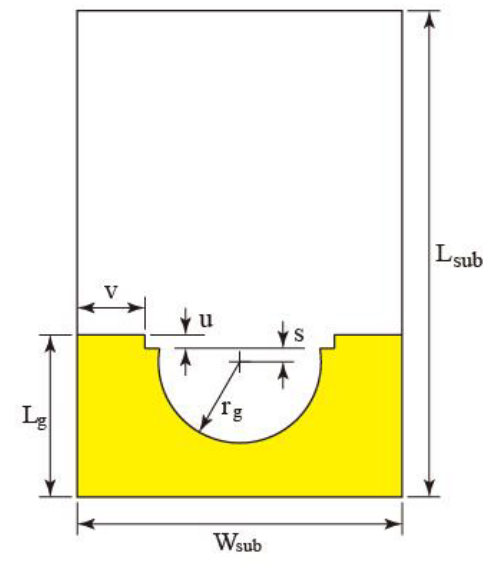

(b)

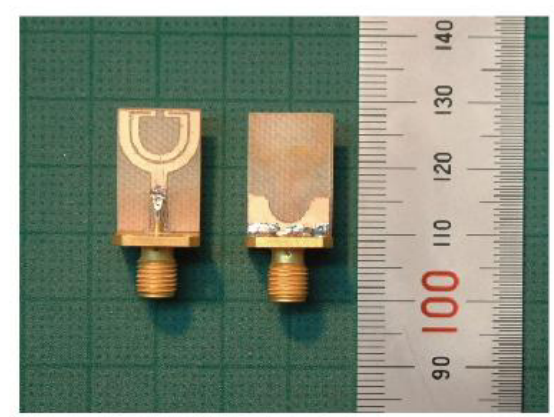

(c)

Fig. 1. Configuration of the proposed antenna, (a) top side, (b) bottom side, and (c) fabricated antennas. 
of the proposed antenna is shown in Fig. 1 (c).

\section{Simulation and experimental results}

In this section, the simulation and experimental work is presented. The antenna is simulated using the Ansoft's HFSS ver.13 simulator which uses the finite element method (FEM) in the analysis. The performance of the antenna is measured using a vector network analyzer (Anritsu 37269D). The simulated and measured input reflection coefficients of the proposed antenna are shown in Fig. 2 (a). The antenna is matched $\left(\mathrm{S}_{11}<-10 \mathrm{~dB}\right)$ over the frequency band from $3.1 \mathrm{GHz}$ to $11 \mathrm{GHz}$ while the frequency band from $3.4 \mathrm{GHz}$ to $4.1 \mathrm{GHz}$ is rejected.

Fig. 2 (b) displays the gain of the proposed antenna. The figure shows a deep notch in the gain of the antenna at the WiMAX frequency band. At this frequency band, the slot acts as a tank circuit which resonates to disturb the impedance matching. According to Fig. 2 (a), the value of $\mathrm{S}_{11}$ at the center frequency of the rejected band is about $-2 \mathrm{~dB}$. Only less than the half of the input power is accepted by the antenna, while a small portion of the accepted power is radiated and the rest of the power is dissipated inside the antenna. This means that the radiation of the antenna at the rejected band is too weak. The radiation efficiency of the antenna is shown in Fig. 2 (c).

To measure the group delay of the antenna, two antenna elements are used in an anechoic chamber. The two antennas are spaced by $50 \mathrm{~cm}$. The measured group delay of the antenna is shown in Fig. 2 (d) and its value is approximately constant at 2 ns over the entire operating frequency band. This in turn means that, the proposed antenna has a good degree of fidelity in data transmission.

Figs. $2(\mathrm{e}), 2(\mathrm{f}), 2(\mathrm{~g})$, and $2(\mathrm{~h})$ show the surface current distribution of the proposed antenna at the frequencies $3.3 \mathrm{GHz}, 3.5 \mathrm{GHz}, 4.6 \mathrm{GHz}$, and 8.6 GHz respectively. Fig. 2 (f) shows the effect of the slot on the performance of the antenna at the WiMAX frequency band. The length of the slot is chosen to be the half of the effective wavelength at the center frequency of the band that we want to reject. The center frequency in this case is chosen to be $f_{c}=3.5 \mathrm{GHz}$. The total length of the slot $l_{s}$ can be computed using this expression:

$$
l_{s}=c /\left\lfloor 2 f_{c} \sqrt{\left(\varepsilon_{r}+1\right) / 2}\right\rfloor,
$$

where $c$ is speed of light.

The introduced slot acts as a parallel LC circuit, and as it is known, the impedance of the parallel LC circuit tends to be maximum at resonance. Consequently, the current fed at resonance is minimum. At the same time there is a small current circulating inside the resonance circuit. In our antenna case, the same phenomenon takes place, as there is a mismatch between the antenna and the feeder at the resonance frequency $f_{c}$, only a small portion of the power is fed to the antenna and this power appears as a concentrated surface current around the slot as shown in Fig. 2 (f). By comparing the current distribution shown in Fig. 2 (f) with that of Figs. $2(\mathrm{e}), 2(\mathrm{~g})$, and 


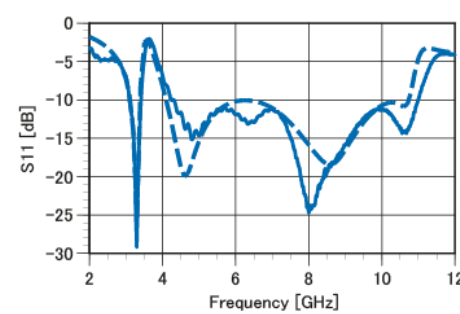

(a)

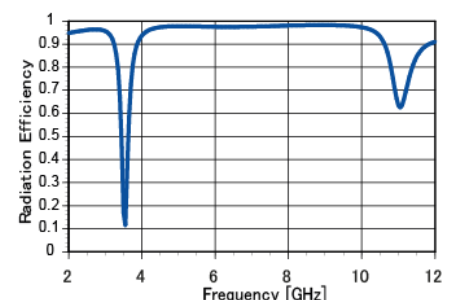

(c)

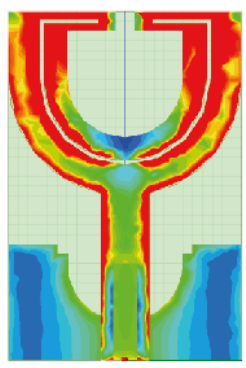

(e)

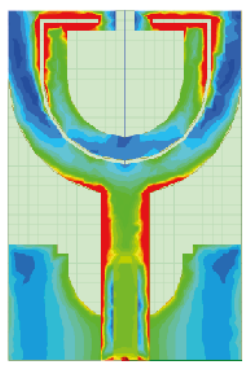

(g)

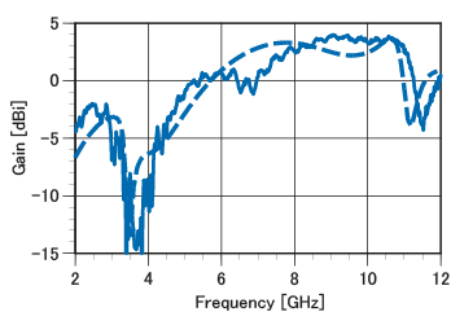

(b)

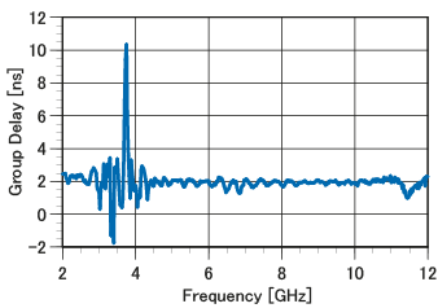

(d)

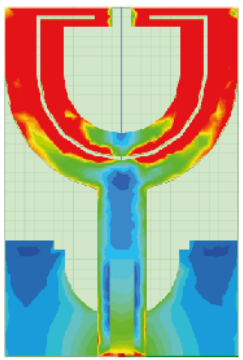

(f)

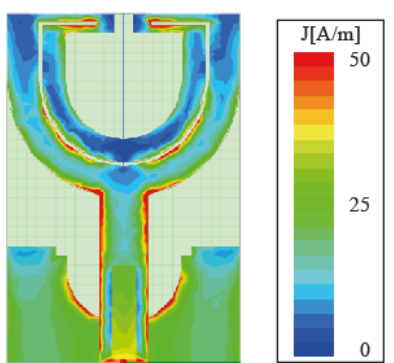

(h)

Fig. 2. (a) Simulated (dashed) and measured (solid) input reflection coefficients, (b) simulated (dashed) and measured (solid) gain, (c) radiation efficiency, (d) measured group delay, (e) surface current at $3.3 \mathrm{GHz}$, (f) surface current at $3.5 \mathrm{GHz}$, (g) surface current at $4.6 \mathrm{GHz}$, (h) surface current at $8.6 \mathrm{GHz}$.

$2(\mathrm{~h})$, we observe a discontinuity in the path of the feeder current at $3.5 \mathrm{GHz}$, which indicates power rejection. In contrast, we can observe a continuous path of the feeder current at $3.3 \mathrm{GHz}, 4.6 \mathrm{GHz}$, and $8.6 \mathrm{GHz}$.

Fig. 3 shows the simulated and measured radiation pattern of the proposed antenna. The co-polarized and cross-polarized radiation patterns are depicted at three frequencies $3.3 \mathrm{GHz}, 5 \mathrm{GHz}$, and $10 \mathrm{GHz}$. As it is shown in the figure, the E-plane pattern of the antenna is bi-directional while the $\mathrm{H}$-plane pattern is omni-directional. The antenna presents satisfactory radiation characteristics over the intended frequency band with good agreement between the simulated and measured radiation patterns. 

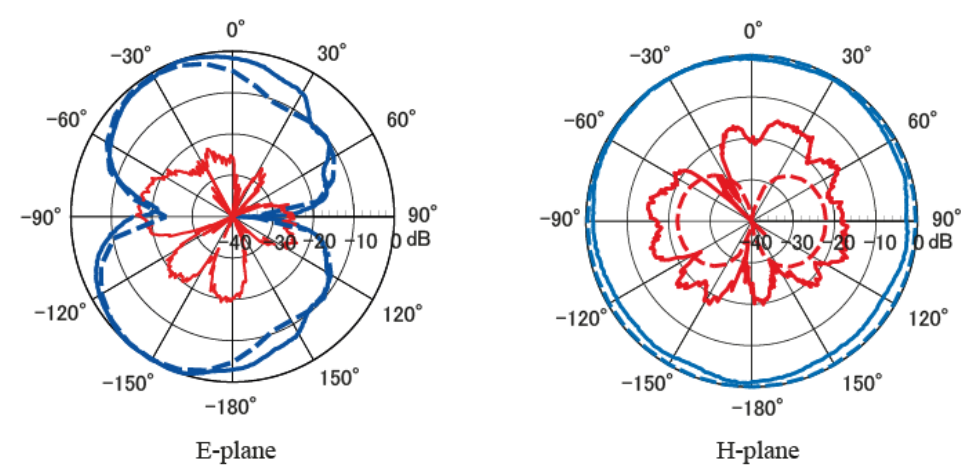

(a)
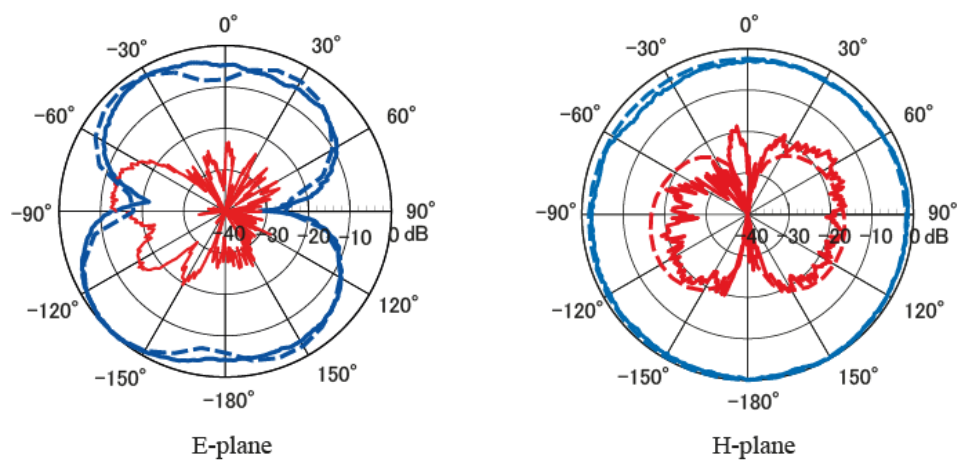

(b)
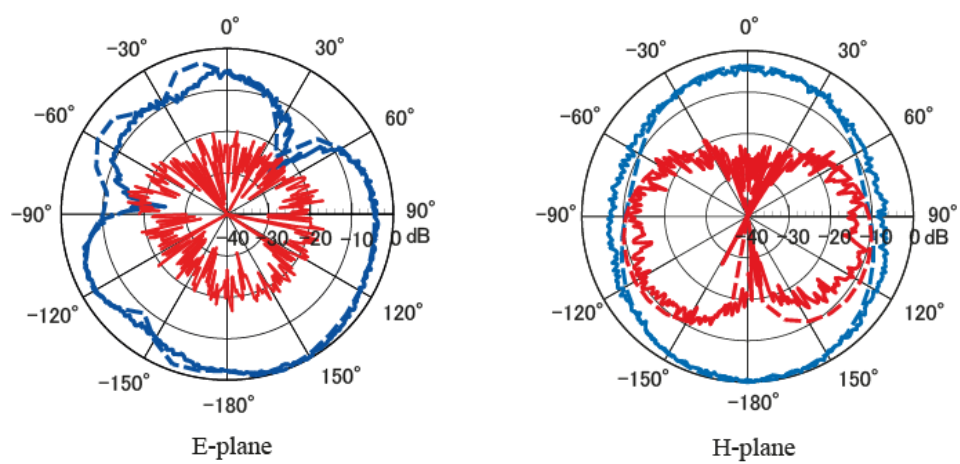

(c)

Fig. 3. Simulated and measured radiation patterns at (a) $3.3 \mathrm{GHz}$, (b) $5 \mathrm{GHz}$, and (c) $10 \mathrm{GHz}$. (Blue line: co-polar, red line: cross-polar, solid line: measured, dashed line: simulated).

\section{Conclusion}

A compact size UWB monopole antenna with WiMAX band rejection is proposed in this paper. The proposed antenna is characterized by its highly compact size and simple configuration. The antenna is simulated, fabricated, and measured. The results show good performance of the antenna and good agreement between the simulation and measurements. 